\title{
Evaluating training for a simulated team in complex whole procedure simulations in the endovascular suite
}

\author{
DEBRA NESTEL, ISABELLE VAN HERZEELE, RAJESH AGGARWAL, KEVIN ODONOGHUE, \\ ANDREW CHOONG, RACHEL CLOUGH, CHRISTOPHER EADES, JENNA LAU, SIMON NEEQUAYE, \\ GURPAL AHLUWALIA \& ARA DARZI \\ Imperial College, London
}

\begin{abstract}
Introduction: Simulators supporting the development of technical skills for complex procedures are gaining prominence. Safe performance of complex procedures requires effective team interactions. Our research group creates 'whole' procedure simulations to produce the psychological fidelity of clinical settings. Recruitment of real interventional team (IT) members has proved challenging. Actors as a simulated team are expensive. We hypothesised that medical students and trainees in a vascular unit could authentically portray members of the endovascular suite for carotid stenting.

Methods: This paper describes the evaluation of a training programme for a simulated IT. Participants rated the extent to which programmes objectives were met and realism of simulations. Researchers' field notes provided insight into strengths and weaknesses of the programme.

Results: Seven members from the vascular unit undertook training. Learning objectives were largely met. Nineteen simulations with 13 interventionalists were performed. Realism levels were at least moderate. Simulated IT members reported increased understanding of teamwork and roles in the endovascular suite.

Discussion: A simulated IT proved feasible. Authentic psychological fidelity complemented the physical fidelity of the simulated suite. Although there were areas for development in training, this approach might contribute considerably to interventionalist training and increase knowledge and skills of vascular trainees and medical students.
\end{abstract}

\section{Introduction}

Our research team has developed a humanistic approach to using simulation to support clinicians in acquiring complex surgical and procedural skills (Kneebone et al. 2006a, b, 2008). We aim to recreate the physical and psychological fidelity of real work environments so that clinicians can practise in settings in which they will be expected to work. This means developing simulations that reflect the technical and human elements of sophisticated work environments. Although interventionalists may have expertise in technical elements of a procedure, their performance is in part team-dependent. Clinicians are likely to benefit from rehearsing complex technical and non-technical skills in the context in which they will be practised. Theory underpinning this approach to learning through simulation is derived from studies of expertise (Ericsson 2004) and communities of practice in which learning is 'situated' or contextualised (Lave \& Wenger 1991; Wenger 1998) together with reflective practice (Schon 1987). The educational value of simulation has been reported by Issenberg et al. (2005).

Learning in simulation is ethically appropriate. This is especially the case in high risk procedures with a definite

\section{Practice points}

- If you are submitting an article please provide up to 5 short bullet points which summarise the key messages of the article. These will be included in a box at the end of the article.

- Contextualised procedural simulations are growing in importance for clinical training.

- Tensions between service and training can place constraints on entire real operating or interventionalist teams attending simulations.

- This paper provides guidance on training medical students and vascular trainees as members of a simulated interventionalist team.

learning curve such as carotid artery stenting (CAS) (Connors et al. 2005; Bates et al. 2007). Clinicians can learn new techniques without negative consequences to patients. Training can be tailored to meet the needs of individual clinicians and occur in a structured manner as opposed to chance encounters in the clinical setting (Neequaye et al. 2007b). This approach also enables assessment in a range of

Correspondence: Professor Debra Nestel, Gippsland Medical School, Monash University, Northways Road, Churchill, 3842 , Victoria, Australia. Tel: +6139902 6201; fax: +6139902 6841; email: debra.nestel@med.monash.edu.au 
different scenarios including those beyond their level of experience, prior to interventions performed on real patients (Dayal et al. 2004; Aggarwal et al. 2006; Hsu et al. 2004; Van Herzeele et al. 2007; Reznick \& MacRae 2006; Patel et al. 2006; Hislop et al. 2006; Neequaye et al. 2007a).

There are several reasons for working with simulated teams. Clinical service needs are always greater than training and in our experience it has proven difficult and expensive to set up simulations which are cancelled because clinicians have these competing demands. Simulated teams can be scheduled with less risk of cancellation. Although there are examples of theatre and other teams attending training together it is not always possible nor is it always appropriate. Simulated teams enable learning to focus on an individual within a team (e.g. cardiologist, radiologist, vascular surgeon, neuro-radiologist) and are therefore time efficient for the involved clinician. Actors have played the roles of health care professionals (e.g. anaesthetists, scrub nurse, operating department assistant) in the operating theatre for complex operations (Black et al. 2006; Nestel et al. 2008). This enables 'standardisation' of performances and the level of challenge can be adjusted. However, it is relatively expensive to train and pay actors.

Simulated teams required for highly specialised work environments need expertise if they are to achieve high fidelity. In this study surgical trainees and medical students were willing to give their time in return for learning new skills. With this valuable resource and a limited budget, we developed a training programme in which surgical trainees and medical students were recruited to play the roles of health care professionals in a simulated interventional team (IT) in an endovascular suite. We have not identified any published work that describes this or similar approaches.

We hypothesised that there would be several advantages to working with junior colleagues rather than actors in a simulated IT.

- They already have some knowledge of the endovascular suite, therefore they are likely to pick up technical elements of the scenario.

- They are already familiar with medical jargon.

- They are likely to have a greater repertoire of authentic responses at hand for unrehearsed prompts from interventionalists.

- By playing the roles of other members of the health care team, they are likely to increase their understanding of how the whole team functions and the importance of effective teamwork in complex environments.

Possible disadvantages of the approach are that junior colleagues may:

- bring preconceived ideas about team roles.

- feel threatened by behaviours associated with characters (e.g. playing an assistant with unprofessional behaviour) with senior colleagues with whom they may work one day.

- lack confidence and ability in role-play.

Although the field of simulation is expanding rapidly there are very few published papers on the preparation of simulated teams for whole procedure simulations.
Carotid artery stenting (CAS) and the endovascular suite

CAS is performed to prevent stroke in patients who have recently had a transient ischemic attack, a stroke or who have a significant stenosis $(>60 \%)$ of the carotid artery. CAS has a steep learning curve evidenced by the reduced number of procedure-related complications, fluoroscopic time and contrast volume that occur in clinical practice as a result of increased interventionalist experience. CAS is regarded as a challenging procedure and has a very high risk of serious complications if carried out by an inexperienced interventionalist (Sacks \& Connors 2005; Gaines \& Nicholson 2006; Bates et al. 2007)

Although there are individual, hospital and national differences in CAS teams they usually consist of an interventionalist, assistant, scrub nurse, radiographer and a circulating nurse handling the endovascular tools. The interventionalist may be a vascular surgeon, interventional radiologist, neuro-radiologist or interventional cardiologist. The performance of a clinician in the context of an IT can be assessed during a simulated CAS procedure prior to interventions on real patients. If necessary, further individual (or group training) can be provided to improve technical and non-technical skills to enhance patient safety.

As part of a research project on the assessment of performance in CAS, interventionalists were recruited to perform CAS in whole procedure simulations designed to assess technical and non-technical skills. This provided an opportunity to evaluate the feasibility of simulated IT training programme.

The principal research question is: "To what extent is it feasible to train junior clinicians and medical students to function as a simulated IT?" Additionally, we wanted to identify the strengths and areas of development of the training programme and to explore the short-term impact on simulated IT members.

\section{Methods}

The simulated IT training programme included the following.

- A written guide setting out the objectives of the training programme, its relationship to the broader research programme, a statement of expected commitments (attend training session and research days) and role descriptions. Box 1 provides an example of the likely steps an interventionalist would take in a CAS simulation and Box 2 outlines the role of the nurse. The full training programme is available on request from the corresponding author (DN). Roles were partially drafted by two authors (DN \& IH) and finalised with project participants during the training session.

- A 6-hour training session was conducted which relied heavily on experiential activities with the aims of explaining the goals of the training and CAS research project, casting and clarifying roles for the endovascular suite, rehearsing technical and character aspects of IT roles, rehearsing two complete simulations and using the Non-technical Operating Theatre Skills for Surgery (NOTSS) rating form 
- The 'patient' has already had local anaesthetic $(\llcorner\mathrm{A})$, is draped and the introducer sheath in place when the interventionalist enters the endovascular suite. The interventionalist will check the available imaging (e.g. duplex scan, angiogram, MRA, CTA) and the haemodynamic stability of the patient.

- The interventionalist commences by introducing a guide wire and pigtail catheter to perform an arch aortic angiogram. The technician will be asked to adjust the $\mathrm{C}$-arm to LAO $30-45^{\circ}$. Some experts might skip this phase and directly cannulate the common carotid artery since a picture of the aortic arch is available in the 'patient's records'.

- The common carotid artery will be selectively cannulated and a guiding catheter or guiding sheath will be introduced. A new angiogram will be performed and the $\mathrm{C}$ arm might need further adjustment to have an optimal view of the carotid bifurcation. Depending on the interventionalist, he/she will ask the anesthetist to administer heparin before or after selective cannulation of the common carotid artery (5000-7500 units IV).

- Most often an embolic protection system will be used. In the majority of cases a filter will be used which is usually mounted on a 0.014 wire. This filter wire needs to remain stable at all times.

- The procedure continues with the interventionalist using a balloon and a self expandable stent to treat the lesion. Some interventionalists will always pre-dilate, others selectively pre-dilate the lesion using a coronary balloon. It is likely that the interventionalist will ask for atropine (1 mg) or glycopyrrolate (600 micrograms) intravenously. Some will have asked for these drugs at the beginning of the procedure. The self expandable stent is sized to the diameter of the common carotid artery. The post-dilation balloon is sized to the diameter of the internal carotid artery.

- A completion angiogram will be performed and once satisfied, the EPD will be removed. The remaining endovascular tools will be removed and the procedure is finished at which point the scenario ends.

Box. 2 Example of the role for the nurse in the CAS simulation.

\section{Character}

- Your name is Andrew Brent

- You are polite and co-operative

- You do not respond to aggressive behaviors with mimicry

- Do not initiate conversation except that which directly relates to your tasks

- You respond to questions the interventionalist asks you as helpfully as you can

- You have been doing this work for 4 years

- You enjoy your work

Tasks

- You will be handling instruments (via the computer)

- You need to know the process of the CAS procedure to enable you to track the interventionalist's progress carefully

- Complete an observation form on non-technical skills for surgeons (NOTSS) observation form after every scenario

- Record your rating of scenario realism

Non-stressful scenario

- You hand instruments on time every time anticipating requests and being highly co-operative

Stressful scenario

- You will receive a social phone call at a critical moment in the procedure (During the stent phase). Talk unless you are asked to stop - at least for a few minutes

(Yule et al. 2006a, b). Figure 1 shows team members rehearsing a CAS scenario in the simulated endovascular suite.

\section{CAS simulated scenarios}

Two scenarios were developed using the same carotid lesion to assess the technical and non-technical performance of endovascular physicians with varying experience in CAS during a simulated procedure. The interventionalist is required to perform an identical non-complex right sided CAS. The nurse started each scenario by introducing the IT, the patient and the case to the interventionalist. Props that are used in real practice were incorporated in the simulations (e.g. patient records).

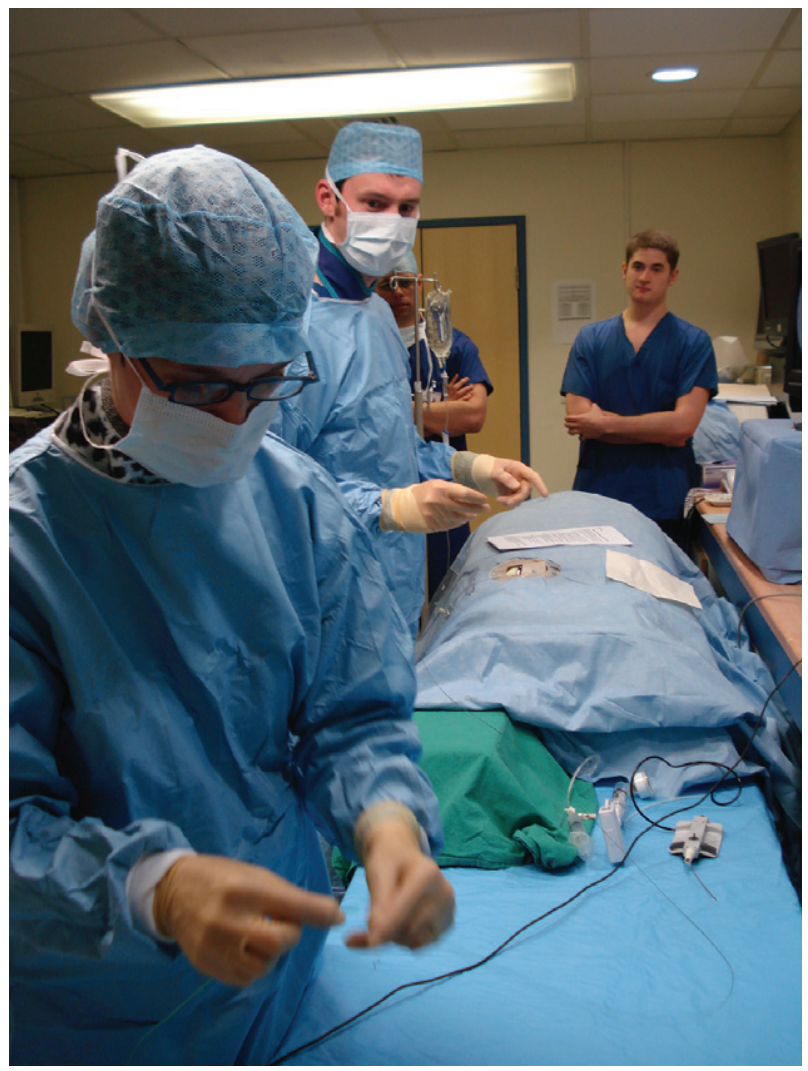

Figure 1. The simulated interventional team in training in the simulated endovascular suite.

During scenario one, the interventionalist is assisted by an 'experienced' team, no errors were intentionally made by the team members and all were very helpful offering advice to the clinician if thought appropriate or necessary.

During scenario two, the following potentially stressful events occurred.

- The experienced nurse was called away while presenting the case to the interventionalist (briefing). A replacement nurse entered the room and introduced herself to the physician informing him/her that she was less experienced than her colleague. 
- During the intervention, the radiographer bumps into the C-arm after an aortic arch angiogram had been performed.

- The nurse pulls out the guide wire while exchanging the diagnostic catheter for a guiding catheter or sheath.

- The filter wire is pulled excessively by the nurse during deployment.

- Prior to pre-dilation and/or stenting the anaesthesist leaves the interventional suite for coffee.

- The circulating nurse receives a social phone call during the stenting phase and does not stop talking for about 5 minutes unless asked by the interventionalist.

The technical performance of the interventionalist was assessed using the metrics recorded by the virtual reality simulator (www.mentice.com) and by post-hoc videoratings using a validated approach to the assessment of surgical skills (Martin et al. 1997). Non-technical performance was assessed using NOTSS with judgements made by each member of the simulated IT. These data are currently being analysed and form part of the broader research programme.

Formal ethics committee approval was not required as the study was considered of low negative impact for participants. The voluntary status of all participants was emphasised and they were aware that they could withdraw from the project at anytime without consequence.

\section{Evaluation methodology}

There were two parts to the evaluation.

\section{Training session}

Simulated IT members' independently used a scale from 'not at all' (1) to 'completely' (6) to rate the degree to which they met the learning objectives of the training session and the value of the activities designed to achieve them (Table 2). Immediately afterwards they participated in a group interview that sought their views on what had worked well, what needed to be improved and what further training they required.

Two researchers $(\mathrm{DN} \& \mathrm{IH})$ made field notes throughout the training day.

\section{Research days}

In March 2007, volunteer interventionalists were recruited to the study during an international vascular and endovascular meeting. We constructed a simulated interventional suite in the exhibition space. A questionnaire sought basic demographic and professional characteristics (e.g. age, CAS and simulation experience etc). Before scenarios commenced, interventionalists were randomly assigned either the non-stressful (one) or stressful (two) scenario and were familiarised with the simulator. Interventionalists were aware the team was simulated. Interventionalists rated the realism of the team using a scale from 'not at all' (1) to 'completely' (5) realistic. The 5-point scale was used to reflect that used in other projects on scenario realism in our Department. Simulated IT members independently rated the realism of each scenario.

Two researchers (JL \& CE) made field notes throughout the three research days.

\section{Statistics}

Qualitative data were analysed thematically. Basic descriptive statistics were generated with the Statistical Package for the Social Sciences version 15.0 (SPSS, Chicago, Illinois, USA). Mann-Whitney test was used to compare ratings of realism by the simulated IT and interventionalists with $p<0.05$ considered statistically significant (Driscoll \& Lecky, 2001).

\section{Results}

\section{Training session}

There were seven members of the simulated IT - three 4th year medical students, two senior house officers, one junior specialist registrar in general surgery and one senior specialist registrar in vascular surgery. Four team members were male, three female, ranging in age from 21 to 36 years.

Simulated IT members rated five of the six learning objectives with mean scores from 5.1 to 5.4. That is, team members' largely perceived that these objectives had been completely met. The objective on 'confidence in using the NOTSS rating form' was outside this range at 3.6 (Table 1).

For the educational methods, the written materials were rated at 4.6 and technical and non-technical skills practice and discussions at 4.9 (Table 2).

Simulated IT members' suggestions of what worked well included rapid cycle testing two whole scenarios with pauses for review and discussion, the collaborative nature of writing roles, the collegiality, trust and respect demonstrated through the opportunity to work in a sophisticated and complex environment

Suggestions to improve training included more time, especially for the NOTSS observations and observing real interventions. Videotaped materials of CAS were considered

Table 1. Participants' ratings of degree to which they met the learning objectives of the training programme $(1=$ not at all to $6=$ completely $),(N=7)$.

\begin{tabular}{|lccc|}
\hline & Mean & SD & Range \\
& & & \\
Describe the aims of the research project & 5.1 & 0.38 & $1(5,6)$ \\
Clarify my role in the simulations & 5.4 & 0.79 & $2(4,6)$ \\
$\begin{array}{l}\text { Clarify others' roles in the simulations } \\
\text { Be confident to portray technical }\end{array}$ & 5.1 & 0.69 & $2(4,6)$ \\
$\quad$ elements of my role & 5.3 & 0.49 & $1(5,6)$ \\
$\begin{array}{l}\text { Be confident to portray non-technical } \\
\quad \text { elements of my role }\end{array}$ & 5.4 & 0.79 & $2(4,6)$ \\
$\begin{array}{l}\text { Be confident in using NOTSS } \\
\quad \text { observation form }\end{array}$ & 3.6 & 0.79 & $2(2,4)$ \\
\hline
\end{tabular}

Table 2. Participants' ratings of the value of the educational methods in meeting the learning objectives $(1=$ not at all to $6=$ completely), $(N=7)$.

\begin{tabular}{|lccc|}
\hline & Mean & SD & Range \\
& & & \\
Written materials & 4.6 & 0.99 & $2(3,6)$ \\
Technical skills practice and discussions & 4.9 & 0.69 & $2(4,6)$ \\
Non-technical skills practice and discussions & 4.9 & 0.69 & $2(4,6)$ \\
\hline
\end{tabular}


valuable for acquiring technical skills but did not capture the interpersonal climate of the endovascular suite.

The only area for further development cited during the group interview was the opportunity to work with interventionalists of different levels of experience to test the breadth of responses that might be required of the simulated IT.

Field notes identified that scenario one worked effectively while scenario two would need a concerted effort to achieve consistency in timing and intensity of stressors.

\section{Research days}

Over three days, twelve interventionalists participated in nineteen simulations - eleven in scenario one and eight in scenario two. The average time for scenario one was 26 minutes 43 seconds and for scenario two was 29 minutes 26 seconds.

Simulated IT members' mean ratings of realism for scenarios were 3.3 and 3.2 respectively. Mean ratings for all scenarios were 3.2 by simulated IT members. Interventionalists' mean ratings for the scenarios were $4.5(p<0.001)$ (Table 3$)$.

Field notes identified consistency in scenario one over the research days and improving realism and consistency in scenario two as the simulated IT gained experience. Confidence of simulated IT members improved which led to convincing performances. Debriefing with simulated IT members after each scenario proved valuable as did the process of completing evaluation forms. This served to reinforce the importance of consistent and authentic performance. Simulated IT members reported increased understanding of the technical elements of CAS and the roles of all the health care professionals in the endovascular suite. The NOTSS instrument provided a valuable focus for discussion. This was particularly marked for medical students who reported little prior knowledge or experience of such techniques, roles or settings. Simulated IT members reported enjoying the role-play experience and that debriefing helped them switch out of role. Working with different interventionalists created new and sometimes unexpected challenges. All simulated IT members valued the opportunity to work closely over a period of time in a focused and shared activity.

\section{Discussion}

This study shows that it is feasible to train a simulated IT for the endovascular suite based on the ratings of realism from interventionalists (familiar with real endovascular suites) and the simulated IT (less familiarity). It was unexpected that there were no differences in ratings of realism between stressful and non-stressful scenarios since the latter appears to be an

\begin{tabular}{|lccc|}
\hline & Mean & SD & Range \\
Simulated IT members & 3.2 & 0.7 & $2(3,5)$ \\
Interventionalists & 4.5 & 0.8 & $2(3,5)$ \\
\hline
\end{tabular}

unlikely concentration of events. However, immersive simulations can evoke a sense of vivid reality. These simulations appeared to impact all participants in this way, especially the interventionalists manifested by their high overall ratings of realism. The statistically significant difference is surprising given the interventionalists' prior knowledge that the team was simulated.

The evaluation identified the importance for simulated IT members of repeated practise for gaining confidence in consistent performance. Field notes imply the simulated IT developed a group identity through a shared group purpose, highly motivated individuals and a structured programme (post-scenario debriefing and completion of evaluation forms).

Although the training process is labour intensive, simulated IT members enjoyed the experience and reported learning about relationships in the endovascular suite. The opportunity to work with and observe experienced interventionalists was highly valued providing insight to professional interactions that were otherwise inaccessible to the members of the simulated IT.

Simulated IT members rapidly familiarised themselves with language and technical elements relevant to the endovascular suite. They appeared to be highly motivated to gain knowledge and experience.

The principle area for improvement in the training programme was the use of the NOTSS instrument. We were ambitious in expecting confidence in the use of NOTSS after relatively brief training. However, the instrument enabled the simulated IT to critically reflect in a structured way on an individual's behaviour in the context of team-based work in the endovascular suite. The NOTSS instrument introduced parameters of non-technical skills which the simulated IT would have been unlikely to encounter at this stage of their professional training. Simulated IT members reported that they recognised the importance of effective teamwork within the endovascular suite. It is worth noting that NOTSS was designed for use in the operating theatre and may not transfer directly to the endovascular suite.

Our initial hypotheses are difficult to measure. Compared with an earlier study with actors as health care professionals, the simulated IT quickly adjusted to the language and relatively unfamiliar behaviours of the endovascular suite. Even though the medical students had limited prior clinical exposure, they were already experiencing 'secondary socialisation,' the process by which individuals become members of a profession. Simulated IT members did not comment on their confidence of using and understanding medical language which was perceived as a significant challenge for actors (Nestel et al. 2008).

There was no evidence of the disadvantages of the approach we outlined earlier. Simulated IT members did not report any insurmountable difficulties associated with role-play. Debriefing post-scenario was important to move out of role.

\section{Limitations of the study}

There are obvious limitations to the study including the small sample size, self-selection of the simulated IT team, the study 
was confined to one procedure and took place in one vascular training unit. The rating scales may not have been sufficiently discriminating to detect fine grained differences in realism between scenarios. Participants may also have been confused by the ue of 5- and 6-point scales. Self-report of meeting learning objectives may not be reliable although field notes suggest learning occurred. Further, we did not have a control group with a real interventional team. The notion of asking simulated IT members to rate 'realism' when they have minimal direct experience of that reality is also contentious.

Future studies should address these limitations and investigate the longer term impact on health care professionals taking on simulated IT roles especially as they relate to acquiring knowledge and skills for effective team-based work. Such simulations may be a valuable means of helping trainees explore future career choices.

\section{Concluding remarks}

The study was set within a broader research programme on promoting safe practice in CAS interventions. This paper has focused on the feasibility of a training programme for a simulated IT made up of junior clinicians and medical students and the benefits that may accrue to them. The evaluation suggests that the training programme for the simulated IT is valuable. Given that simulation-based education is increasing it is important that ways to maximise benefits for all participants are explored.

\section{Notes on contributor}

At the time of the study, all authors were associated with the Department of Biosurgery and Surgical Technology, Imperial College London.

\section{References}

Aggarwal R, Black SA, Hance J, Darzi A, Cheshire NJW. 2006. Virtual reality simulation training can improve inexperienced surgeons' endovascular skills. Eur J Vasc Surg 31(6):588-93.

Bates ER, Babb JD, Casey DE, Cates CU, Duckwiler GR, Feldman TE, Gray WA, Ouriel K, Peterson ED, Rosenfeld K, Rundback JH, Safian RD, Sloan MA, White CJ, Harrington RA, Abrams J, Anderson JL, Eisenberg MJ, Grines CL. 2007. ACCF/SCAI/SVMB/SIR/ASITN 2007 clinical expert consensus document on carotid artery stenting: A report of the American College of Cardiology Foundation Task Force on Clinical Consensus Documents. J Am Coll Cardiol 49(1):126-70.

Black SA, Nestel D, Horrocks E, Harrison R, Jones N, Wetzel C, Kneebone RL. 2006. Evaluation of a framework for case development and simulated patient training for complex procedures. Sim Healthcare 1(2):66-71.

Connors JJ, Sacks D, Furlan AJ, Selman WR, Russell EJ, Stieg PE, Hadley MN, The Neurovascular Coalition Writing Group. 2005. Training, competency and credentialing standards for diagnostic cervicocerebral angiography, carotid stenting, and cerebrovascular intervention: A joint statement from the American Academy of Neurology, the American Association of Neurological Surgeons, the American Society of Interventional and Therapeutic Neuroradiology, the American Society of Neuroradiology, the Congress of Neurological Surgeons, the AANS/CNS Cerebrovascular Section, and the Society of Interventional Radiology. Neurology 64(2):190-198.
Dayal R, Faries PL, Lin SC, Bernheim J, Hollenbeck S, De Rubertis B, Trocciola S, Rhee J, Mckinsey J, Morrissey NJ, Kent C. 2004. Computer simulation as a component of catheter-based training. J Vasc Surg 40(6):1112-1117.

Driscoll P, Lecky F. 2001. An introduction to hypothesis testing. Nonparametric comparison of two groups. Emerg Med J 18:276-282.

Ericsson KA. 2004. Deliberate practices and the acquisition and maintenance of expert performance in medicine and related domains. Acad Med 79(10):S70-81.

Gaines P, Nicholson T. 2006. A suggested training programme for carotid artery stenting. Euro J Radiol 60(1):37-39.

Hislop SJ, Hsu JH, Narins CR, Gillespie BT, Jain RA, Schippert DW, Almudevar AL, Illig KA. 2006. Simulator assessment of innate endovascular aptitude versus empirically correct performance. J Vasc Surg 43(1):47-55.

Hsu JH, Younan D, Pandalai S, Gillespie BT, Jain RA, Schippert DW, Narins CR, Khanna A, Surowiec SM, Davies M, Shortell CK, Rhodes J, Waldman DL, Green RM, Illig KA. 2004. Use of computer simulation for determining endovascular skill levels on a carotid artery stenting model. J Vasc Surg 40(6):1118-1125.

Issenberg BS, McGaghie WC, Petrusa ER, Lee G, Scalese R. 2005. Features and uses of high fidelity medical simulators that lead to effective learning: A BEME systematic review. Med Teach 27:10-28.

Kneebone R, Nestel D, Bello F, Darzi A. 2008. An Integrated Procedural Performance Instrument (IPPI) for learning and assessing procedural skills. Clin Teach 5:45-48.

Kneebone R, Nestel D, Yadollahi F, Brown R, Nolan C, Durack J, Brenton H, Moulton CA, Darzi A. 2006b. Assessing procedural skills in context: An Integrated Procedural Performance Instrument (IPPI). Med Educ 40(11):1105-1114.

Kneebone RL, Nestel D, Wetzel CM, Black S, Jacklin R, Aggarwal R, Yadollahi F, Wolfe J, Vincent C, Darzi A. 2006a. The human face of simulation. Acad Med 81(10):919-924.

Lave J, Wenger E. 1991. Situated Learning. Legitimate Peripheral Participation. Cambridge University Press: Cambridge.

Martin JA, Regehr G, Reznick R, Macrae H, Murnaghan J, Hutchison C, Brown M. 1997. Objective structured assessment of technical skill (OSATS) for surgical residents. Br J Surg 84(2):273-278.

Neequaye SK, Aggarwal R, Brightwell R, Van Herzeele I, Darzi A, Cheshire NJW. 2007a. Identification of skills common to renal and iliac endovascular procedures performed on a virtual reality simulator. Euro J Endovasc Surg 33(5):525-532.

Neequaye SK, Aggarwal R, Van Herzeele I, Darzi A, Cheshire NJW. 2007b. Endovascular skills training and assessment. J Vasc Surg 46(5): 1055-1064.

Nestel D, Black S, Wetzel C, Kneebone R, Thomas P, Wolfe JHN, Darzi A. 2008. Simulated anaesthetists in high fidelity simulations for surgical training: Feasibility of a training programme for actors. Med Teach April: $1-4$

Patel AD, Gallagher AG, Nicholson WJ, Cates CU. 2006. Learning curves and reliability measures for virtual reality simulation in the performance assessment of carotid angiography. J Am Coll Cardiol 47(9):1796-1802.

Reznick RK, Macrae H. 2006. Teaching surgical skills - changes in the wind. New Eng J Med 355(25):2664-2669.

Sacks D, Connors JJ. 2005. Carotid stent placement, stroke prevention and training. Radiology 234(1):49-52.

Schon D. 1987. Educating the Reflective Practitioner: Toward a new design for teaching and learning in the professions. San Francisco: Jossey-Bass.

Van Herzeele I, Aggarwal R, Choong A, Brightwell R, Vermassen FE, Chechire NJ. 2007. Virtual reality simulation objectively differentiates level of carotid stent experience in experienced interventionalists. J Vasc Surg 46(5):855-863.

Wenger E. 1998. Communities of Practice. Learning, Meaning, and Identity. Cambridge: Cambridge University Press.

Yule S, Flin R, Paterson-Brown S, Maran N. 2006a. Non-technical skills for surgeons in the operating room: A review of the literature. Surgery 139(2):140-149.

Yule S, Flin R, Paterson-Brown S, Maran N, Rowley D. 2006b. Development of a rating system for surgeons' non-technical skills. Med Educ 40(11):1098-1104. 